\title{
Spinocerebellar ataxia type 11
}

INSERM

\section{Source}

INSERM. (1999). Orphanet: an online rare disease and orphan drug data base.

Spinocerebellar ataxia type 11. ORPHA:98767

Spinocerebellar ataxia type 11 (SCA11) is a subtype of autosomal dominant cerebellar ataxia type III (ADCA type III; see this term) characterized by the early-onset of cerebellar signs, eye movement abnormalities and pyramidal signs. 